\title{
Anterior segment optical coherence tomography in the assessment of intrastromal corneal ring segment position
}

\author{
Karolína Kapitánová ${ }^{1,2 *}$, Jaroslav Nikel $^{1}$, Peter Žiak ${ }^{1,2}$ and Juraj Halička ${ }^{1,2}$ \\ ${ }^{1}$ UVEA Mediklinik Inc., Martin, Slovakia \\ ${ }^{2}$ Department of Ophthalmology; Jessenius Faculty of Medicine in Martin, Comenius University in Bratislava, Slovakia
}

\begin{abstract}
Introduction: Aim of the presented work was an evaluation of the position of the intrastromal corneal ring segments (ICRS) twelve months after their implantation in eyes with keratoconus or marginal pellucid degeneration.

Methods: Included in the study group were 11 eyes with keratoconus or with marginal pellucid degeneration with implanted ICRS. The position of the implanted segments was evaluated twelve months after surgery with high resolution anterior segment optical coherence tomography (AS-OCT) raster scans. Moreover, corneal topography, uncorrected visual acuity - UCVA, and best corrected visual acuity - BCVA were examined.

Results: Stromal thickness over the ICRS reached in the proximal end of the implant $212.1 \mu \mathrm{m}$, in the central part $226.9 \mu \mathrm{m}$ and in the distal end $228.0 \mu \mathrm{m}$ on average. Stromal thickness under the implant was $188.2 \mu \mathrm{m}$ proximally, $167.5 \mu \mathrm{m}$ centrally and $169.0 \mu \mathrm{m}$ distally on average. Corneal topography mostly proved stable (81.8\%) when compared with early postoperative findings. In the twelve-month follow-up, UCVA improved in 7 eyes (63.6\%) and BCVA in 6 eyes (54,5\%).

Discussion: No segment prone to extrusion was found in the study group. UCVA and BCVA, as well as the corneal topography findings, were stable. Patients with implanted ICRS can be successfully checked by means of AS-OCT to detect the segment position or migration of the segment with possible subsequent extrusion.
\end{abstract}

\section{Introduction}

Keratoconus is a bilateral, progressive, non- inflammatory corneal disease. Its pathogenesis is multifactorial and remains basically unknown. While its multifactorial origin is accepted, the genetic component has a major role. There are extreme variations in the disease prevalence with an approximately four times higher incidence among Asians compared to Caucasians [1]. The disease impairs the quantity and quality of vision secondary to the progressive thinning and protrusion of the cornea. This results in an irregular astigmatism with or without myopisation [2].

Intracorneal ring segments (ICRS) are arcuate elements made of medical grade polymethylmethacrylate (PMMA). They represent a microinvasive approach to the treatment of keratoconus and corneal ectasia (after laser refractive procedures, trauma etc.). They have a refractive effect (visual acuity improvement, optical aberrations correction) as well as a stabilizing influence (reduction of the disease progression). An important advantage of ICRS implantation is the reversibility of the procedure. Moreover, the postoperative state is suitable for combination with another treatment (rigid contact lenses, corneal cross- linking or intraocular surgery). The arcuate shape and thickness of the ring segment has great importance. The larger the arc, the greater is its effect on spherical refraction. On the other hand, the smaller the arc, the greater is its effect on the cylindrical refraction. Thicker arches are more effective overall. Long-term studies show favorable outcomes in uncorrected and best-corrected visual acuity (UCVA and BCVA) improvement, as well as in corneal topography findings [2].

The first step in ICRS implantation is the creation of a corneal tunnel. For this purpose, there are two options: the manual separation of the corneal stroma or the femtosecond laser-assisted technique. The first option is accompanied with a higher risk of perioperative complications, therefore the femtosecond laser, introduced in 2003, meant precise intrastromal cutting and more, significant safety and other advantages with comparable visual acuity improvement compared to current manual techniques [3]. The femtosecond laser makes the implantation considerably faster and more comfortable for the patient [4]. The second part of the implantation process is the insertion of the ICRS in the prepared tunnel.

There are two widely available types of ICRS: Intacs (Addition Technology, Inc., Lombard, USA) and Keraring (Mediphacos, Ltd., Belo Horizonte, Brazil). Keraring is the direct descendent of Ferrara ring, only differing in the number of available segment lengths and being designed specifically for keratoconus [5]. It has a triangular profile and the arc length is $340^{\circ}$ maximally.

MyoRing (Dioptrex GmbH, Linz, Austria) is the only $360^{\circ}$ full ring implant with published clinical data. It is implanted within the corneal stromal pocket. Its ability to reduce the spherical equivalent is greater than in the corneal ring segments [1].

*Correspondence to: Karolína Kapitánová, UVEA Mediklinik Inc., Martin; Department of Ophthalmology; Jessenius Faculty of Medicine in Martin, Comenius University in Bratislava, Slovakia, Tel: +421 915530 669; +421 4203 557; +421 434012 600; E-mail: kapitanova.k@gmail.com

Key words: keratoconus, ICRS implantation, stromal thickness, high-resolution raster scans

Received: June 26, 2018; Accepted: August 10, 2018; Published: August 13, 2018 
The correct position and depth of the ICRS after implantation are crucial. Shallow implantation is often associated with complications such as corneal thinning, implant extrusion, anterior stromal compression or the defective diffusion of nutrients to the corneal epithelium. Therefore, an assessment of the ICRS location may be useful for predicting possible subsequent complications [6]. The most important steps are represented by the slit lamp examination and also the anterior segment optical coherence tomography (AS-OCT). The latter provides for a very precise assessment [7].

The aim of this study was to prove the benefits of AS- OCT in the evaluation of ICRS position. Intrastromal segment location was examined to determine if there were any changes in segment emplacement or any signs of segment migration in the late postoperative period.

\section{Materials and methods}

This study is a prospective evaluation of a group of 11 eyes with keratoconus or marginal pellucid degeneration. All patients underwent Keraring ICRS implantation in one eye or in both eyes with the aid of the femtosecond laser (Victus, Bausch + Lomb, New York, USA; software version 2.7.1077.1) at the UVEA Mediklinik eye hospital in Martin. All surgeries were undetaken between August 2015 and September 2016. AS- OCT scans were used for the evaluation of the implant position approximately twelve months postoperatively. All patients provided informed consent prior to treatment and study entry. Contraindication for the surgery was the presence of corneal edema, central corneal scarring, corneal inflammation, intensive atopy, recurrent corneal erosions as well as inadequate patient expectations. In the ICRS calculation process there are three critical factors: type of corneal asymmetry based on the corneal topography findings, corneal pachymetry and subjective patient refraction. Keraring calculation specifically is based on 4 types of corneal asymmetry (Figure 1). Nomograms provided by the manufacturer are then used for the ICRS selection. For types 1 and 2 Nomogram A was applied, for type 3 Nomogram B was applied and for type 4 Nomogram C was applied.

Minimal preoperative central corneal thickness was $380 \mu \mathrm{m}$; only in one eye was it $330 \mu \mathrm{m}$. Minimal corneal thickness in the implantation site was $375 \mu \mathrm{m}$. Corneal pachymetry in the implant trajectory was checked and the bottom of the stromal tunnel was situated at 75 to $80 \%$ of corneal thickness. The manufacturer delivered the ICRS together with the materials determining all parameters of the implantation (segment position and length, incision axis, tunnel width and depth).

The surgical technique was performed under topical anesthesia after adequate preparation at the operation site. The femtosecond laser-assisted tunnel creation started with the disposable suction ring placement and centration on the corneal surface. Some of the femtosecond laser parameters were identical for all eyes - the energy used for tunnel creation (1000 nJ), tunnel spot spacing $(6 \mu \mathrm{m})$, tunnel line spacing $(6 \mu \mathrm{m})$, incision spot spacing $(5 \mu \mathrm{m})$ and incision line spacing $(2 \mu \mathrm{m})$. The incision was then made on the steepest topographic axis with energy $1500 \mathrm{~nJ}$ (Figure 2). The Keraring segments were then manually inserted in the prepared stromal channels. In the study group SI5 type was used in 10 eyes (14 ring segments) and SI6 type in 1 eye (2 ring segments). The incision site was sutureless. There were no perioperative complications recorded in our group. Postoperative treatment consisted of topically administered antibiotic and corticosteroid eye drops used for 4 to 6 weeks.

Anterior segment OCT was performed approximately twelve months postoperatively in all mentioned eyes (Cirrus HD 4000, Carl

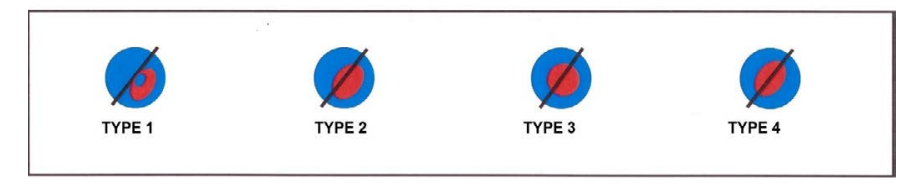

Figure 1. Types of corneal asymmetry used for Keraring calculation
After ICRS Tunnel
Op CAM

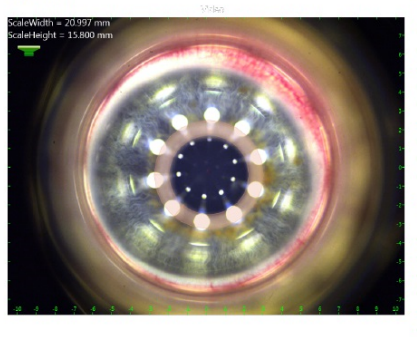

OCT-Bscan $0^{\circ} /$ OCT-Cscan

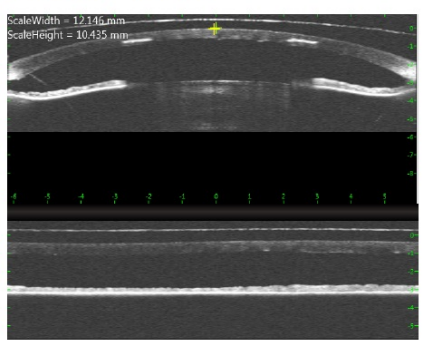

Figure 2. Photo of the anterior segment and AS- optical coherence tomography - results of femtosecond laser-assisted corneal tunnel creation

Zeiss Meditec, Inc.). Multiple high definition 5- line raster scans were taken in the central part and also in the proximal and distal end of each segment. Scans were done with a $0^{\circ}$ angle, $0.25 \mathrm{~mm}$ spacing and 3.00 $\mathrm{mm}$ length. High resolution scans were then analyzed to evaluate if there were any signs of ICRS migration or any shifts in the primary position of the implant. During this examination corneal topography as well as evaluation of the uncorrected visual acuity (UCVA) and bestcorrected visual acuity (BCVA) were also provided.

\section{Results}

The present study group included 11 eyes from 7 patients $(5 \mathrm{men}$, 2 women). The mean age of the patients was 46.6 years (ranging from 29 to 72 years old). In the whole group there were 10 eyes (90.9\%) with keratoconus, all presenting morphology of the paracentral (oval) type.

Based on the Amsler- Krumeich classification 8 eyes (72.7\%) matched the $3^{\text {rd }}$ grade of keratoconus and 2 eyes $(18.2 \%)$ the $2^{\text {nd }}$ grade. None of evaluated eyes matched the $1^{\text {st }}$ or $4^{\text {th }}$ grade of keratoconus due to Amsler- Krumeich classification. The last eye $(9.1 \%)$ had pellucid marginal degeneration.

The average preoperative corneal thickness in the implantation site was $412.27 \mu \mathrm{m}$ (from $375 \mu \mathrm{m}$ to $460 \mu \mathrm{m}$ ) and the intended depth of segments was on the level of 75 to $80 \%$, indicating an average value of $316 \mu \mathrm{m}$ (range $270 \mu \mathrm{m}$ to $360 \mu \mathrm{m}$ ). Average stromal thickness under the segment was $96.5 \mu \mathrm{m}$ (range $75 \mu \mathrm{m}$ to $110 \mu \mathrm{m}$ ). Based on ASOCT (Figure 3), stromal thickness over the ICRS twelve months after the implantation varied in the proximal end from 140 to $350 \mu \mathrm{m}$ (on average $212.1 \mu \mathrm{m}$ ), in the central part of the implant from 132 to 336 $\mu \mathrm{m}$ (on average $226.9 \mu \mathrm{m}$ ) and in the distal end it was between 132 and $350 \mu \mathrm{m}$ (on average $228 \mu \mathrm{m}$ ). Stromal thickness under the implant was from 100 to $316 \mu \mathrm{m}$ (on average $188.2 \mu \mathrm{m}$ ) proximally, from 72 to $281 \mu \mathrm{m}$ (on average $167.5 \mu \mathrm{m}$ ) centrally and between 60 to $304 \mu \mathrm{m}$ (on average $169 \mu \mathrm{m}$ ) distally. Certain values of corneal thickness above and under the implants are given in Table 1.

Corneal topography did prove the stability of the corneal curvatures in 9 eyes $(81.8 \%)$ with no signs of progression of corneal ectasia. The rest of the evaluated group - 2 eyes (18.2\%) - showed a minimal increase in keratometry values (Figure 4 ). The actual UCVA and BCVA values were also compared with the preoperative values. Visual acuity was examined on the Topcon CC-100XP LED LCD system based on 
High Definition Images: Anterior Segment 5 Line $\quad O D \bullet \mid O$ OS

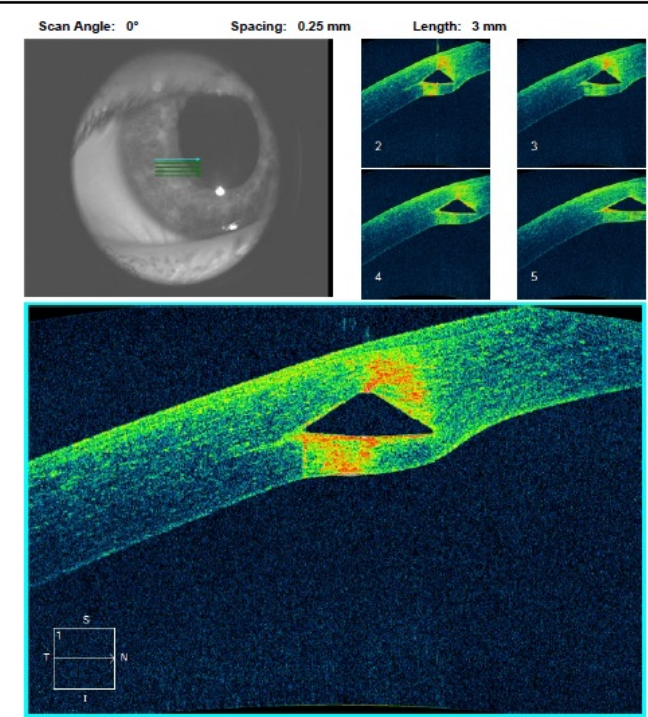

Figures 3. Anterior segment high resolution OCT scans - three different eyes, three different findings

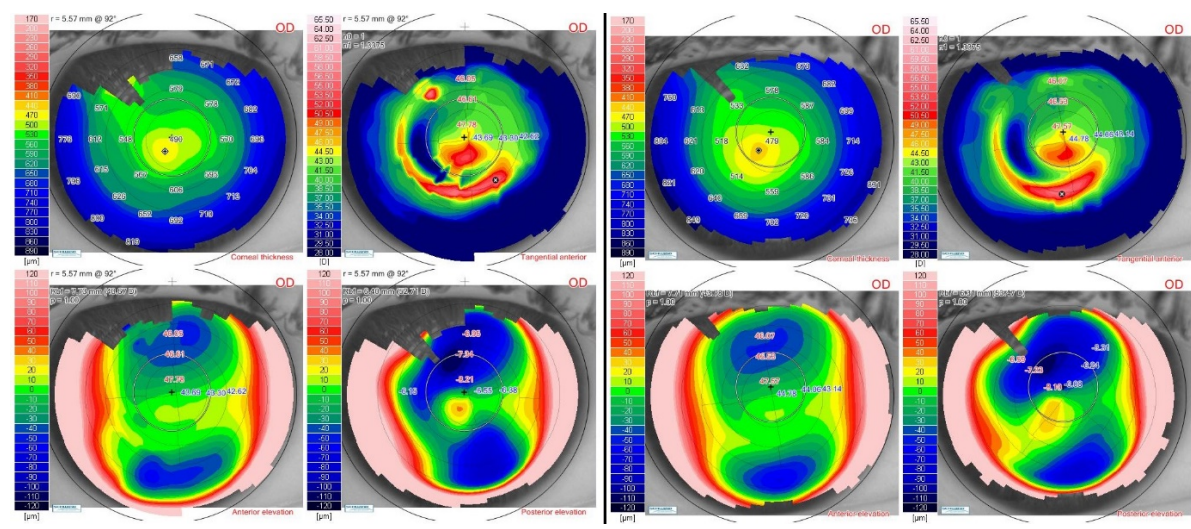

Figure 4. Corneal topography of the same eye three months and one year after ICRS implantation

Table 1. Certain values of corneal thickness above and under the implants

\begin{tabular}{|c|c|c|c|c|c|c|c|}
\hline \multirow[t]{2}{*}{ EYE } & \multirow[t]{2}{*}{ ICRS } & \multicolumn{3}{|c|}{ Stromal thickness above the ICRS } & \multicolumn{3}{|c|}{ Stromal thickness under the ICRS } \\
\hline & & Proximally $(\mu \mathrm{m})$ & Centrally $(\mu \mathrm{m})$ & Distally $(\mu \mathrm{m})$ & Proximally $(\mu \mathrm{m})$ & Centrally $(\mu \mathrm{m})$ & Distally $(\mu \mathrm{m})$ \\
\hline 1 & $\mathbf{A}$ & 185 & 204 & 156 & 230 & 228 & 248 \\
\hline 2 & B & 156 & 184 & 212 & 216 & 168 & 144 \\
\hline \multirow[t]{2}{*}{3} & $\mathbf{C}$ & 350 & 336 & 350 & 148 & 160 & 132 \\
\hline & D & 168 & 224 & 224 & 144 & 100 & 152 \\
\hline \multirow[t]{2}{*}{4} & $\mathbf{E}$ & 185 & 141 & 170 & 244 & 281 & 304 \\
\hline & $\mathbf{F}$ & 200 & 163 & 170 & 126 & 104 & 126 \\
\hline \multirow[t]{2}{*}{5} & G & 200 & 244 & 252 & 222 & 274 & 256 \\
\hline & $\mathbf{H}$ & 259 & 222 & 170 & 244 & 193 & 207 \\
\hline 6 & $\mathbf{I}$ & 274 & 267 & 259 & 178 & 148 & 148 \\
\hline 7 & $\mathbf{J}$ & 140 & 180 & 216 & 316 & 204 & 204 \\
\hline \multirow[t]{2}{*}{8} & $\mathbf{K}$ & 212 & 270 & 270 & 148 & 132 & 132 \\
\hline & $\mathbf{L}$ & 148 & 132 & 132 & 260 & 240 & 244 \\
\hline 9 & $\mathbf{M}$ & 208 & 264 & 276 & 192 & 136 & 104 \\
\hline 10 & $\mathbf{N}$ & 228 & 208 & 224 & 128 & 88 & 88 \\
\hline \multirow[t]{2}{*}{11} & $\mathbf{O}$ & 216 & 280 & 252 & 115 & 152 & 156 \\
\hline & $\mathbf{P}$ & 264 & 312 & 316 & 100 & 72 & 60 \\
\hline \multicolumn{2}{|c|}{ AVERAGE } & 212,06 & 226,93 & 228,06 & 188,18 & 167,50 & 169,06 \\
\hline \multicolumn{2}{|c|}{ RANGE } & $140-350$ & $132-336$ & $132-350$ & $100-316$ & $72-281$ & $60-304$ \\
\hline
\end{tabular}

ICRS: Intrastromal corneal ring segment 
the Snellens principle. In the twelve-month follow-up, UCVA improved in 7 eyes $(63.6 \%)$, stayed unchanged in 1 eye $(9.1 \%)$ and decreased in 3 eyes $(27.3 \%)$. The decrease reached 1 line.

BCVA was improved in 6 eyes $(54.5 \%)$ or stayed unchanged in 5 eyes (45.5\%). The improvement in UCVA varied from 1 to 4 lines.

Based on measurements taken one year after implantation, no segment was prone to extrusion. Mild changes in segment position did not endanger its function or the visual acuity of the patient. This stayed unchanged and stable in all 11 examined eyes (100\%) in comparison with UCVA and BCVA values six months after the surgery.

All patients included in this study were subjectively satisfied with the long-term result of the surgery. In addition, a mild improvement in their visual acuity and the stabilization of the disease progression meant subjective success for each patient and an enhancement in their quality of life.

\section{Discussion}

The examination of the anterior segment OCT is a modern and accurate method for evaluating ICRS position. As part of the femtosecond laser, it is used intraoperatively to assess the femtosecond laser-created tunnel. The qualitative and quantitative evaluation of the intrastromal tunnel by AS- OCT before the implantation of the ring segments is a practical intraoperative approach that may offer a safer surgery [6]. In the postoperative period AS-OCT is widely used for checks of the implant [7-10].

Mild shifts in ICRS location are possible and they may result in a shallower final position of the implanted segment than expected. In the case of implant extrusion with the local formation of corneal ulceration, an amniotic membrane can be used such as in the treatment of other ocular surface disorders [11].

\section{Conclusion}

In the study group there was no segment prone to extrusion based on the AS-OCT examination. UCVA and BCVA remained unchanged and in a majority of the examined eyes the keratometries were also stable.
Nevertheless, AS-OCT is useful in every patient with implanted ICRS. It can be applied as a reliable predictor of an imminent complication - the migration of the implanted segment to the corneal surface, especially to the incision site with possible subsequent extrusion.

\section{References}

1. Alió JL (2017) Keratoconus. Recent advances in diagnosis and treatment. Cham: Springer Internation Publishing Switzerland.

2. Jadidi K, Mosavi SA, Nejat F, Naderi M, Janani L, et al. (2015) Intrastromal cornea ring segment implantation (Keraring $355^{\circ}$ ) in patients with central keratoconus: 6-month follow-up. J Ophthalmol 2015: 916385. [Crossref]

3. Ratkay-Traub I, Ferincz IE, Juhasz T, Kurtz RM, Krueger RR (2003) First clinica results with the femtosecond neodynium-glass laser in refractive surgery. $J$ Refract Surg 19: 94-103. [Crossref]

4. Coskunseven E, Kymionis GD, Tsiklis NS, Atun S, Arslan E, et al. (2011) Complications of intrastromal corneal ring segment implantation using a femtosecond laser for channel creation: a survey of 850 eyes with keratoconus. Acta Ophthalmol 89: 54-57. [Crossref]

5. Wilde CL, Naylor SG, Varga Z, Morrell A, Ball JL (2017) Keraring implantation using the Zeiss Visumax femtosecond laser in the management of patients with keratoconus. Eye (Lond) 31: 916-923. [Crossref]

6. Kucumen RB, Gorgun E, Yenerel NM, Utine CA (2012) Intraoperative use of ASOCT during intrastromal corneal ring segment implantation. Ophthalmic Surg Lasers Imaging 43: S109-S116. [Crossref]

7. Barbara R, Barbara A, Naftali M (2016) Depth evaluation of intended vs actual intacs intrastromal ring segments using optical coherence tomography. Eye (Lond) 30: 102110. [Crossref]

8. Gorgun E, Kucumen RB, Yenerel NM, Ciftci F (2012) Assessment of intrastromal corneal ring segment position with anterior segment optical coherence tomography. Ophthalmic Surg Lasers Imaging 43: 214-221. [Crossref]

9. Lai MM, Tang M, Andrade EM, et al. (2006) Optical coherence tomography to assess intrastromal corneal ring segment depth in keratoconic eyes. J Cataract Refract Surg 32: 1860-1865. [Crossref]

10. Naftali M, Jabaly-Habib H (2013) Depth of intrastromal corneal ring segments by OCT. Eur J Ophthalmol 23: 171-176. [Crossref]

11. Krčová I, Stanislavová M, Peško K, Furdová A, Koller J (2016) Amniotic membrane applications - our experience. Cesk Slov Oftalmol 72: 204-208. [Crossref]

Copyright: (C2018 Kapitánová K. This is an open-access article distributed under the terms of the Creative Commons Attribution License, which permits unrestricted use, distribution, and reproduction in any medium, provided the original author and source are credited. 